\title{
LAS AUTORIZACIONES DE PESCA Y EL DERECHO DE PROPIEDAD
}

["Fishing Authorizations and Right to Property"]

\author{
Jessica Fuentes Olmos* \\ Pontificia Universidad Católica de Valparaíso, Chile
}

\begin{abstract}
RESUMEN
El artículo analiza la supuesta calidad de bien incorporal que tendrían las autorizaciones de pesca. Desde la perspectiva constitucional se distinguen los planos objetivo y subjetivo de la propiedad, el concepto de bien incorporal, la naturaleza de la autorización de pesca y sus diferencias con la concesión y el permiso. Concluye negando la calidad de bien incorporal a la autorización de pesca pues no otorga un derecho independiente de la libertad para adquirir toda clase de bienes, ni genera efectos patrimoniales por sí misma, porque ellos dependerán del régimen de acceso a la pesca vigente.

Palabras Clave

Autorización de pesca - Bien incorporal - Derecho de propiedad
\end{abstract}

\begin{abstract}
This article analyzes the alleged quality of intangible property of fishing authorizations. From the constitutional perspective, the objective and subjective levels of property, the concept of intangible property, the nature of the fishing authorization and the differences with concession and permit are highlighted. This work concludes by stating that the fishing authorization does not have the quality of intangible property, since it neither grants a right independent from the freedom to acquire any kind of properties nor generates patrimonial effects for itself, since they depend on the access regime to fishing currently in force.

\section{KEYWORDS}

Fishing authorization - Intangible property - Right to property.
\end{abstract}

ReCibido el 23 de abril y ACEPTADo el 22 de mayo de 2012.

* Profesora de Derecho Constitucional en la Facultad de Derecho de la Pontificia Universidad Católica de Valparaíso. Dirección postal: Bellavista 168, edificio Centenario, piso 18, Valparaíso, Chile. Correo electrónico: fo.jessica@gmail.com 


\section{INTRODUCCIÓN**}

En la actualidad, la mayoría de las pesquerías nacionales relevantes para el sector de pesca industrial, se encuentra sometido a un régimen imperfecto de cuotas individuales ${ }^{1}$ por armador. En efecto, debido a la sobreexplotación del recurso jurel desde fines de los años noventa, en el año 2001 se emitió la ley No 19.713 sobre "límite máximo de captura por armador" que estableció cuotas individuales para los armadores industriales basadas en la historia de pesca previa de cada armador (derechos históricos) y, en algunos casos, a la capacidad de captura de las naves del armador, pero dichas cuotas están asociadas a las naves que contaban con autorizaciones de pesca vigentes en cada pesquería.

Si bien el "límite máximo de captura por armador" fue concebido originalmente como una medida que sólo duraría dos años, por Ley № 19.849 fue prorrogada su vigencia por otros 10 años. El 31 de diciembre de 2012 vencerán los 10 años y de no dictarse otra ley, se volverá al régimen previo de la Ley No 19.713, esto es, la actividad pesquera sometida a alguno de los regímenes de acceso previstos en la LGPA.

Una presentación realizada ante el Tribunal de la Libre Competencia por parte de una empresa pesquera adelantó la discusión acerca del régimen de acceso y de asignación de cuotas en el sector pesquero industrial, planteándose como alternativa a lo existente, la licitación de las cuotas de captura. A raíz de esta discusión acerca de licitar las cuotas de pesca que eventualmente puedan fijarse a partir de 2013, renunciando a asignarlas por derechos históricos, se planteó la cuestión desde el punto de vista del derecho de propiedad, acerca de las consecuencias del término de las autorizaciones de pesca vigentes.

El objetivo de este trabajo es dilucidar si corresponde afirmar un derecho de propiedad susceptible de ser afectado por la creación de un sistema de acceso y asignación totalmente nuevo. Más específicamente, se trata de determinar si puede afirmarse la calidad de bien incorporal de las autoriza-

** CC.: Código Civil; C.Pol.: Constitución Politica de la República; LGPA.: Ley General de Pesca y Acuicultura $\mathrm{N}^{\circ} 18.892$, cuyo texto refundido, coordinado y sistematizado fue fijado por Decreto supremo No 430, de 1991, del Ministerio de Economía, Fomento y Reconstrucción.

${ }^{1}$ Suele decirse que se trata de un régimen imperfecto de cuotas individuales porque en un régimen perfecto de cuotas individuales transferibles (o ITQ como son conocidas por su sigla en inglés), éstas no están asociadas a una nave específica y, además, pueden ser transferidas libremente entre distintos armadores. Como se verá, en el régimen de "límite máximo de captura por armador" (cuota de pesca), la cuota surge y se mantiene vinculada a cada nave autorizada al armador y su transferencia tiene como restricción la de poderse ejecutar solo en cuanto la autorización se transfiera juntamente con la nave. 
ciones de pesca para efectos de establecer la eventual afectación del derecho de propiedad mediante una ley que regule un nuevo régimen de acceso a la actividad de pesca industrial o establezca una nueva forma de asignación de cuotas para los armadores industriales.

Para tales efectos el presente trabajo se ha dividido de la siguiente manera: en primer lugar, se plantea el estado de la cuestión acerca de los bienes incorporales protegidos susceptibles del derecho de propiedad; en segundo lugar, se abordan los fundamentos constitucionales de la regulación pesquera; en tercer lugar, se expone sintéticamente la regulación de acceso a la actividad pesquera industrial; en cuarto lugar, se analiza la naturaleza de la autorización de pesca desde el punto de vista doctrinario, de su regulación en la LGPA. y los argumentos esgrimidos en esta materia ante el Tribunal de la Libre Competencia por constituir lo más reciente en cuanto a esta discusión; en quinto lugar, se analizará la autorización de pesca y la posibilidad de su protección ante el legislador a través de la propiedad y por último se expondrán las conclusiones del presente trabajo.

\section{LOS BIENES INCORPORALES PROTEGIDOS}

CONSTITUCIONALMENTE POR EL DERECHO DE PROPIEDAD.

ESTADO DE LA CUESTIÓN

La Constitución, en su artículo $19 \mathrm{~N}^{\circ} 24$, asegura el derecho de propiedad en sus diversas especies sobre toda clase de bienes corporales e incorporales (inciso $1^{\circ}$ ). Asimismo, se contempla la reserva legal, esto es, que sólo el legislador puede establecer el modo de usar, gozar y disponer de ella y las limitaciones y obligaciones que se derivan de su función social (inciso $2^{\circ}$ ). Finalmente, y en lo pertinente para los efectos del presente apartado, se consagra la inviolabilidad de la propiedad en cuanto se regula la institución de la expropiación como forma de intervención del derecho de propiedad, sometida al cumplimiento de las condiciones constitucionales que, en términos generales, se refieren a la legalidad de la medida, su causa sustentada en la utilidad pública o el interés nacional, la indemnización del daño patrimonial efectivamente causado y sus garantías específicas, así como la reclamación judicial por la ilegalidad del acto o el monto de la indemnización (incisos $3^{\circ}, 4^{\circ}$ y $\left.5^{\circ}\right)$.

A la fecha persiste una confusión conceptual en torno a los diversos planos del derecho de propiedad que encuentran amparo en el artículo $19 \mathrm{~N}^{\circ} 24$ C.Pol., al concepto de bien incorporal y de limitación y privación.

Desde el punto de vista de la protección constitucional al derecho de 
propiedad, Aldunate y Cordero ${ }^{2}$ distinguen dos planos: uno objetivo y otro subjetivo, los que se encontrarían consagrados en los incisos $2^{\circ}$ y $3^{\circ}$ del artículo $19 \mathrm{~N}^{\circ} 24$ C.Pol. respectivamente. De este modo, el inciso $2^{\circ}$ resguardaría la reserva legal, las limitaciones y obligaciones fundadas en la función social y el derecho real que otorga a su titular las facultades de uso, goce y disposición sobre un bien corporal, reconocido y reconocible como el instituto del dominio. En relación a esto último, al indicarse en el artículo $19 \mathrm{~N}^{\circ} 26$ C.Pol. que las disposiciones legales que regulen o complementen las garantías constitucionales, en los casos que la Carta así lo autoriza, no podrán afectar los derechos en su esencia ni imponer condiciones, tributos ni requisitos que impidan su libre ejercicio, debe entenderse, en el caso de la propiedad prevista en el artículo $19 \mathrm{~N}^{\circ} 24$, referida a ese núcleo esencial del derecho de dominio (uso, goce y disposición) que no es disponible por el legislador. Esto porque además el artículo $19 \mathrm{~N}^{\circ} 26$ se refiere claramente a los casos en que la propia Constitución entrega al legislador la regulación o complementación de las garantías, lo que en el caso del derecho de propiedad se da en el mencionado inciso $2^{\circ}$.

En cambio, en el inciso $3^{\circ}$ del artículo $19 \mathrm{~N}^{\circ} 24$ C.Pol. se encontraría consagrada la protección constitucional del aspecto subjetivo de la propiedad, esto es, el patrimonio de cada particular en cuanto resulta intangible por el Estado, previéndose solo la posibilidad de la intervención expropiatoria.

Con el planteamiento anterior, se puede distinguir la extensión de la protección constitucional de la propiedad sobre bienes corporales (dominio) y el ámbito que no puede ser afectado por el legislador mediante la regulación. El legislador tiene plena potestad de regular el instituto del dominio, constituyéndose en inconstitucional su actuación si por la regulación general del instituto se llegase a negar o impedir el ejercicio de las facultades de uso, goce o disposición sobre bienes corporales, puesto que se afectaría el dere-

${ }^{2}$ Aldunate Lizana, Eduardo, Limitación y expropiación. Scilla y Caribdis de la dogmática constitucional de propiedad, en Revista Chilena de Derecho, 33 (Santiago, 2006) 2, pp. 285-303; Deficiencias en la argumentación jurídica. Comentario crítico al fallo del Tribunal Constitucional librado en la causa rol $N^{\circ} 207$, en Revista de Derecho de la Universidad Católica de Valparaíso, 16 (Valparaíso, 1995), pp. 27-44; Jurisprudencia constitucional 2006-2008. Estudio selectivo (Santiago, 2009), pp. 80-85; con Fuentes Olmos, Jessica, El concepto del derecho de propiedad en la jurisprudencia constitucional chilena y la teoria de las garantías de instituto, en Revista de Derecho de la Universidad Católica de Valparaíso, 18 (Valparaíso, 1997), pp. 195-221; Cordero QuinzaCARA, Eduardo, La dogmática constitucional de la propiedad en el Derecho chileno, en Revista de Derecho de la Universidad Austral de Chile, 19 (Santiago, 2006) 1, pp.125-146; Las garantías institucionales en el Derecho alemán y su proyección en el derecho de propiedad, en Revista de Derecho de la Universidad Católica del Norte, 14 (Coquimbo, 2007) 2, pp. 81-99. 
cho en su esencia. Cualquier otra regulación general no alcanza el carácter expropiatorio, aun cuando al cambiar el régimen del dominio pudiese llegar a afectar derechos o meras expectativas de sujetos concretos. En tal caso, la actuación no será inconstitucional sino que trasladará la discusión hacia la igualdad ante las cargas públicas y la responsabilidad del Estado por cuyo acto legislativo se altere dicha igualdad. En tal caso, el problema no es de derecho de propiedad (ni de expropiación) sino de igualdad ante las cargas públicas y la consiguiente responsabilidad del Estado que de ella puede surgir. El principio fundamental de la protección del patrimonio es que a través de las instituciones de la expropiación y la responsabilidad cubren el espectro de lesiones patrimoniales antijurídicas ${ }^{3}$.

Por el contrario, si por ley se pretendiera privar a sujetos concretos de bienes de los que son titulares o de las facultades de uso, goce o disposición, estaríamos en presencia de una ley expropiatoria y, en consecuencia, inconstitucional. Así por ejemplo, cualquier ley que pretendiera que los recintos privados de determinadas características deben destinarse a eventos públicos, se trataría claramente de una privación a sus titulares de la facultad de uso de un bien inmueble y, por ende, sería inconstitucional.

Como puede apreciarse la importancia de la distinción entre los planos objetivo y subjetivo es relevante para dilucidar la extensión de la potestad legislativa y su relación con la protección constitucional de la propiedad. La confusión de ambos planos ha llevado a que en ocasiones se reconozca un verdadero derecho a la mantención de una determinada regulación legislativa ${ }^{4}$, aunque acudiendo a la categoría de la propiedad sobre bienes incorporales.

Se puede preguntar, entre otras: ¿qué son los bienes incorporales? ¿Qué es lo que se protege con el derecho de propiedad sobre bienes incorporales? ¿Existe un contenido esencial de la propiedad sobre bienes incorporales? ¿Debe el legislador respetar un contenido reconocido y reconocible hoy como propiedad sobre bienes incorporales?

Los bienes son las cosas susceptibles de apropiación, las que conforme con el artículo 565 CC. pueden ser cosas corporales o incorporales. Las primeras tienen un ser real y son perceptibles por los sentidos, en tanto, las segundas consisten en meros derechos.

${ }^{3}$ Montt Oyarzún, Santiago, Aplicación de los tratados bilaterales de protección de inversiones por tribunales chilenos. Responsabilidad del Estado y expropiaciones regulatorias en un mundo crecientemente globalizado, en Revista Chilena de Derecho, 32 (Santiago, 2005),1.

${ }^{4}$ Sentencia del Tribunal Constitucional, rol N ${ }^{\circ} 207$, sobre deuda subordinada, comentado por Aldunate Lizana, E., Deficiencias en la argumentación jurídica. Comentario crítico al fallo del Tribunal Constitucional librado en la causa rol $N^{\circ} 207$, cit. (n. 2). 
Siguiendo la doctrina sentada por Guzmán ${ }^{5}$ en esta materia puede señalarse que la relación entre cosas y bienes es más bien de extensión, todos los bienes son cosas pero no todas las cosas son bienes, puesto que existen cosas que no tienen carácter patrimonial, así por ejemplo, los derechos extra patrimoniales (de la personalidad, derechos constitucionales) son cosas incorporales pero no bienes. Dado que se está hablando del derecho de propiedad, en consecuencia, necesariamente se está hablando de cosas de carácter patrimonial. La Constitución, entonces, utilizó un lenguaje más preciso con la expresión "bienes" para referirse a las cosas incorporales sobre los que recae el derecho de propiedad, por lo cual ellas deben tener carácter patrimonial. Se excluye así de la propiedad los derechos que no tienen carácter patrimonial como son los derechos constitucionales porque de ellos somos titulares por el solo hecho de ser personas y no son susceptibles de apropiación ${ }^{6}$.

En cuanto a lo que se protege con la propiedad sobre bienes incorporales, se tiene, por una parte, la tesis de Guzmán construida sobre las normas civiles, que sostiene que la propiedad sobre bienes incorporales del artículo 583 CC. no se identifica en una relación género-especie con el dominio del artículo 582 CC., sino que se trataría de una especie de propiedad así como lo es el mismo dominio y la propiedad sobre las producciones del talento y del ingenio del artículo 584 CC. En consecuencia, los artículos 582, 583 y 584 CC. tratarían tres especies de propiedad cuya característica común que define, en consecuencia, el contenido del género propiedad es su carácter de p ro pio en oposición a ajeno, esto es, el contenido de la propiedad es una titula $\mathrm{rid} \mathrm{ad}^{7}$ exclusiva sobre el bien de que se trate (sea corporal, incorporal o producción el ingenio o talento).

En consecuencia, al hablar de propiedad sobre bienes incorporales se alude a la protección de la titularidad de derechos de carácter patrimonial.

A la pregunta sobre el contenido esencial de la propiedad sobre bienes incorporales debe responderse negativamente puesto que como se dijo más arriba, la garantía del artículo $19 \mathrm{~N}^{\circ} 26 \mathrm{C}$.Pol. está referida a los casos en que la Constitución ordena al legislador la regulación o complementación de una garantía y en el caso del artículo $19 \mathrm{~N}^{\circ} 24$ se da solo respecto del inciso $2^{\circ}$, esto es, con el contenido típico de lo que es el dominio sobre bienes corporales. En efecto y como lo afirma Guzmán ${ }^{8}$, no existe ejercicio de facultades

${ }^{5}$ GUZmÁn BRito, Alejandro, Las cosas incorporales en la doctrina y en el derecho positivo ( $2^{\text {a }}$ edición, Santiago, 2006), p. 55.

${ }^{6}$ Aunque debe reconocerse que se ha dado la práctica de invocar la protección de ciertos derechos constitucionales por la vía de incorporarlos como bienes susceptibles del derecho de propiedad.

${ }^{7}$ Guzmán Brito, A., cit. (n. 5), pp. 136-141.

${ }^{8}$ GUZMÁn Brito, A., Las cosas incorporales, cit. (n. 5), p. 118. 
de uso, disfrute, disposición material (es imposible) ni tenencia sobre bienes incorporales, limitándose su contenido a la disposición jurídica del mismo y, en algunos casos, a legitimar el uso, disfrute, disposición y tenencia, según el tipo de derecho, de la cosa corporal en que inciden ${ }^{9}$. Esto es lógico ya que tratándose de derechos, consisten en ciertos poderes o facultades de a c t u a c i ó $n$, en algunos casos respecto de cosas corporales, única alternativa en que podrían concretarse en actuaciones de carácter material.

Así las cosas, se tiene que los bienes incorporales son derechos, entendidos como poderes o facultades, de carácter patrimonial cuya titularidad exclusiva es reconocida a un sujeto particular, el que puede disponer de ellos. No cabe entonces la referencia a un contenido esencial protegido constitucionalmente puesto que cada bien incorporal tendrá una configuración dada por la fuente que le da nacimiento, en último término, el ordenamiento jurídico que ampara el nacimiento, la titularidad y extinción de ese derecho. Sí cabe, en cambio, la protección constitucional al ejercicio del derecho en el que consiste el bien incorporal y su no afectación en cuanto el individuo mantenga su titularidad mientras no disponga de él voluntariamente.

Por otra parte y a fin de completar la síntesis sobre el estado de la cuestión sobre bienes incorporales se hará una breve referencia a la jurisprudencia. Esta última ha sido vacilante al acoger o desechar acciones de diversa naturaleza referidas a los bienes incorporales. Los tribunales ordinarios han sido bastante erráticos al momento de otorgar amparo, a través del recurso de protección, a supuestos bienes incorporales, incluyendo categorías que dudosa o definitivamente resultan ajenas a toda categoría susceptible de ser considerada como bien incorporal ${ }^{10}$. De la misma forma, el Tribunal Constitucional no ha asentado una línea jurisprudencial precisa que permita construir un concepto de bien incorporal desde el punto de vista constitucional ${ }^{11}$.

Dado que el problema que se aborda en el presente trabajo está referido a la posible afectación del derecho de propiedad por vía de una eventual regulación legal (ley que cambie el sistema de acceso de los recursos hidrobiológicos poniendo término a las autorizaciones de pesca vigentes) es del caso mencionar algunos hitos en torno a la jurisprudencia del Tribunal Constitucional en esta materia. Así, desde la negación a reconocer como bien

${ }^{9}$ Ibíd.

${ }^{10}$ Fuentes Olmos, Jessica, El derecho de propiedad en la doctrina y la jurisprudencia. Recursos de protección e inaplicabilidad 1981-1996 (Santiago, 1998); Olave Alarcón, Cristián, Recurso de Protección, derechos emanados de contratos, derechos emanados de actos administrativos, derechos de funcionarios públicos, derechos previsionales, otros derechos ${ }^{2}$ (Santiago, 1998).

${ }^{11}$ Aldunate Lizana, E., Jurisprudencia constitucional 2006-2008, cit. (n. 2), pp. 80-86. 
incorporal los sistemas de reajustabilidad de las pensiones a sus titulares en los años ochenta, se pasa luego a reconocer propiedad sobre las expectativas de reparto de dividendos a determinado tipo de accionistas de las instituciones financieras ${ }^{12}$, estimando inconstitucional la norma legal que derogaba tal facultad en los años noventa, para luego, en sentencias dictadas en los últimos diez años negar la calidad de bien incorporal, no sólo a calidades que claramente no ostentan dicho carácter (como el empleo público) ${ }^{13}$, o a una determinada regulación que otorga determinados derechos (muellaje ${ }^{14}$, sino que también a derechos derivados de contratos válidamente celebrados (sobre transmisión eléctrica) y a los que se les aplica la legislación modificada, aunque ello implique alterar un elemento sustancial de dichos contratos ya celebrados (plano subjetivo) en términos de modificar el precio pactado ${ }^{15}$.

Lamentablemente la conclusión que se desprende de la jurisprudencia constitucional es que no existe una línea argumental que permita predecir con cierta certeza el destino que podría tener un proyecto de ley que diera término a las autorizaciones de pesca.

\section{Fundamentos Constitucionales DE LA REGULACIÓN PESQUERA}

El artículo $19 \mathrm{~N}^{\circ} 21$ C.Pol. reconoce el derecho a desarrollar cualquier actividad económica que no sea contraria a la moral, al orden público o a la seguridad nacional, respetando las normas legales que la regulen. En consecuencia, siendo la actividad pesquera una actividad económica, se ve resguardada por esta garantía en cuanto su ejercicio se someta a la LGPA. y otras normas complementarias.

Por su parte, la Constitución consagra en su artículo $19 \mathrm{~N}^{\circ} 23$ la libertad para adquirir el dominio de toda clase de bienes, excepto aquellos que la naturaleza ha hecho comunes a todos los hombres o que deban pertenecer a la Nación toda y la ley lo declare así y sin perjuicio de lo dispuesto en otras disposiciones de la misma Constitución (por ejemplo, lo referido al dominio

\footnotetext{
${ }^{12} \mathrm{Rol} \mathrm{N}^{\circ} 207$.

${ }^{13} \mathrm{Rol} \mathrm{N}{ }^{\circ} 1133$.

${ }^{14} \mathrm{Rol} \mathrm{N}^{\circ}$ 467: "Trigésimo séptimo: Que sostener lo contrario importaría la pretensión por parte del titular de una autorización habilitante (ciertamente no convencional o contractual) de un verdadero 'derecho de propiedad' sobre toda la legislación, de modo que se incorporaria al patrimonio de cualquier entidad la totalidad de la normativa vigente al momento de iniciar una actividad económica, la que se petrificaria y sólo podría modificarseprevia expropiación, argumentación que no admite en principio justificación constitucional en atención a la naturaleza del titulo de la requirente" (Considerando 37).

${ }^{15} \mathrm{Rol} \mathrm{N} 505$.
} 
del Estado sobre las minas). Asimismo, la Constitución señala que una ley de quórum calificado y cuando así lo exija el interés general, puede establecer limitaciones o requisitos para la adquisición del dominio de ciertos bienes.

De conformidad con el artículo 606 CC., por la ocupación se adquiere el dominio de las cosas que no pertenecen a nadie, y cuya adquisición no es prohibida por las leyes chilenas, o por el Derecho Internacional, esto es, se trata de un modo de adquirir el dominio. Por su parte, el artículo 607 CC., señala a la pesca y la caza como especies de ocupación por las cuales se adquiere el dominio de los animales bravíos. A su vez, el artículo 608 CC., señala que son animales bravíos o salvajes los que naturalmente viven libres e independientes del hombre, como las fieras y los peces ${ }^{16}$. Conforme con la LGPA., la pesca es una actividad que consiste en capturar, cazar, segar o recolectar recursos hidrobiológicos ${ }^{17}$. En consecuencia, la pesca constituye la actividad mediante la cual opera jurídicamente el modo de adquirir el dominio, ocupación, sobre los recursos hidrobiológicos, entendiendo por tales, todos aquéllos que viven en el medio acuático con prescindencia de la actividad hombre ${ }^{18}$.

Es importante destacar que lo que otorga el dominio sobre los recursos hidrobiológicos es la actividad de captura y no basta, en consecuencia, la organización de las actividades materiales dirigidas a la captura, sino que esta última efectivamente se concrete en la ocupación de recursos hidrobiológicos, sólo así surge el dominio sobre los mismos. Una vez que se ha realizado la captura, surge el derecho de dominio sobre los recursos hidrobiológicos y, en consecuencia, el derecho de propiedad del artículo $19 \mathrm{~N}^{\circ} 24$ C.Pol. sobre ellos.

Ahora bien, la actividad pesquera es una actividad económica que, al basarse en la captura de los recursos hidrobiológicos, supone un riesgo para la conservación de los mismos, ya que por el ejercicio de la libertad de pesca podría llegarse a una situación de sobreexplotación y la consiguiente desaparición de los recursos pesqueros. En virtud del artículo $19 \mathrm{~N}^{\circ} 21$ C.Pol. que asegura a todas las personas el derecho a desarrollar cualquier actividad económica que no sea contraria a la moral, el orden público o a la seguridad nacional, respetando las normas legales que la regulen, es que el Estado regula

${ }^{16}$ Para los efectos de este trabajo no se entrará en la distinción de los diversos recursos hidrobiológicos que realiza la LGPA. entre pelágicos, demersales, bentónicos, mamíferos marinos, etc., porque, como se aprecia, la disposición civil citada plantea un concepto inclusivo de todos ellos.

${ }^{17}$ Especies hidrobiológicas susceptibles de ser aprovechadas por el hombre, artículo $2 \mathrm{~N}^{\circ} 30$ LGPA.

${ }^{18}$ Con esto se excluyen los recursos hidrobiológicos que son objeto de la actividad de acuicultura que consiste en su producción organizada por el hombre. 
el acceso a la actividad pesquera y establece limitaciones y condiciones para su ejercicio.

La potestad del Estado para la regulación de la actividad pesquera en el mar territorial se ejerce de la misma forma que lo hace en el espacio terrestre. Por su parte, la Convención de las Naciones Unidas sobre Derecho del $\operatorname{Mar}^{19}$ reconoce al Estado ribereño, dentro de la zona económica exclusiva ${ }^{20}$, derechos de soberanía para explorar, explotar, conservar y administrar los recursos naturales marinos vivos y no vivos de las aguas suprayacentes al lecho y del lecho y subsuelo del $\mathrm{mar}^{21}$, por lo cual fuera del mar territorial donde se reconoce al Estado jurisdicción plena, son reconocidos por el derecho internacional las potestades públicas de administración y conservación de los recursos hidrobiológicos a que se refiere la autorización de pesca.

En consecuencia, en virtud del artículo $19 \mathrm{~N}^{\circ} 21$ C.Pol., por la necesidad de asegurar la conservación de los recursos hidrobiológicos ${ }^{22}$ y la sustentabilidad de la actividad pesquera, se emitió la LGPA. que establece los requisitos para acceder a la actividad y las limitaciones a que se encuentra sometida. Por este motivo es que la libertad para adquirir el dominio de los recursos hidrobiológicos de que somos titulares, por estar así reconocida en la Constitución y que, en principio no tendría más requisitos que el simple ejercicio de la actividad pesquera o, en términos civiles, por operar el modo de adquirir ocupación (captura de recursos hidrobiológicos), se ve sometida a requisitos y limitaciones. Como se verá más adelante, el requisito de ejercicio estará dado en algunos casos por la titularidad de una autorización de pesca, un permiso extraordinario o la inscripción en un registro. Las limitaciones, en tanto, estarán dadas fundamentalmente por el ejercicio de las facultades estatales de conservación (como establecimiento de vedas, fijación de cuotas de captura, etc.) y de administración de las pesquerías (regímenes de acceso y de asignación de cuotas) que en virtud de esta ley se atribuye al Estado, no por ejercer ninguna especie de dominio sobre dichos recursos, sino por la necesidad de asegurar su conservación, fundándose asíl la potencial intervención estatal en la actividad pesquera ejercida por los particulares.

\footnotetext{
${ }^{19}$ Promulgada por Decreto supremo N ${ }^{\circ} 1383$ de 1997, del Ministerio de Relaciones Exteriores.

${ }^{20} \mathrm{Se}$ extiende en el caso de Chile hasta las 200 millas marinas medidas desde las líneas de base.

${ }^{21}$ Artículo 56 de la Convención de las Naciones Unidas sobre Derecho del Mar.

${ }^{22}$ Artículo $1^{\circ}$ de la LGPA.
} 


\section{REGULACIÓN DEL ACCESO A LA ACTIVIDAD PESQUERA} EN LA LEY GENERAL DE PESCA Y ACUICULTURA

La LGPA. contiene una regulación diversa para la pesca industrial y la pesca artesanal.

En el caso de la pesca artesanal, el artículo 50 LGPA. señala que el régimen de acceso es el de la libertad de pesca, pese a que se requiere la inscripción en un registro que lleva el Servicio Nacional de Pesca y que desde su origen como en sucesivas modificaciones a la LGPA., este principio reconoce importantísimas excepciones ${ }^{23}$. La ley define la pesca artesanal como la actividad que es ejercida en forma personal, directa y habitual por personas naturales, pese a que reconoce la actividad de personas jurídicas, entre las que pueden encontrarse armadores artesanale ${ }^{24}$. Es interesante destacar que es posible cerrar el registro ante la situación de plena explotación de una pesquería, en cuyo caso ante la muerte del pescador dicha inscripción es trasmisible y que recientemente, además fue incorporada a la LGPA. la institución del reemplazo de la inscripción en el registro nacional de pescadores artesanales en pesquerías cerradas, esto es, se permite que el pescador con inscripción en la pesquería cuyo acceso está cerrado pueda ser reemplazado por otro, lo que supone una transferencia de la inscripción ${ }^{25}$.

La LGPA. distingue, en cambio, cuatro regímenes de acceso a la pesca industrial ${ }^{26}$ : general, de plena explotación, de pesquería en recuperación y de pesquería en desarrollo incipiente. En el régimen general de acceso y en el de plena explotación los armadores industriales deben contar con una autorización de pesca. En los de recuperación y desarrollo incipiente se debe contar con un permiso extraordinario de pesca.

Las autorizaciones de pesca corresponden a actos administrativos habilitantes del ejercicio de la actividad pesquera, de carácter indefinido y que están asociadas cada una de ellas a una nave, un armador específico y a unidades de pesquería determinadas (conjunto de actividades pesqueras que se realicen sobre un recurso hidrobiológico en un área determinada). No otorgan una cuota.

En el régimen general de acceso las autorizaciones de pesca son intransferibles, puesto que el acceso a la pesquería no está cerrado y cualquiera podría

${ }^{23}$ Régimen de áreas de manejo y extracción de recursos bentónicos, régimen bentónico de extracción (más conocido por los cupones de loco), régimen artesanal de extracción, todos regímenes de asignación que se fundan en un cierre de acceso previo.

${ }^{24}$ Artículo $2^{\circ} \mathrm{N}^{\circ} 28$ LGPA.

${ }^{25}$ Artículo $50 \mathrm{~A}$.

${ }^{26}$ No será abordada la regulación de la pesca artesanal en detalle por no ser pertinente al presente trabajo. 
solicitarla a la Administración, sin que existan limitaciones al acceso. En cambio, en el régimen de plena explotación, el acceso a la pesquería se cierra por motivos de conservación (dado que las autorizaciones otorgadas representan el máximo esfuerzo pesquero que puede realizarse sobre la pesquería sin colocarla en riesgo ${ }^{27}$ ) y en tal caso, los armadores que habían accedido a autorizaciones antes del cierre y las han mantenido vigentes a la fecha del mismo, se transforman en los únicos habilitados para operar sobre dichas unidades de pesquerías, pueden transferir las autorizaciones junto con la nave y pueden sustituir la nave por otra manteniendo la autorización ${ }^{28}$.

En los regímenes de pesquería en recuperación y en desarrollo incipiente, el acceso está dado por un permiso extraordinario de pesca obtenido en una subasta pública y que, a diferencia de la autorización de pesca, constituye una cuota individual transferible, puesto que se trata de un permiso que habilita la actividad pesquera en una pesquería determinada, sin asociarse a una nave específica, se otorga por un tiempo determinado y representa un porcentaje fijo de la cuota global de captura que se fije cada año, siendo transferible y divisible sin limitaciones.

En la actualidad, en la mayoría de las pesquerías naciones relevantes para el sector de pesca industrial, se encuentra vigente un régimen imperfecto de cuotas individuales ${ }^{29}$ por armador que se construyó sobre la base de las autorizaciones de pesca en otorgadas al amparo de la LGPA. en pesquerías en plena explotación. En efecto, en el año 2001 se libró la Ley No 19.713 sobre "límite máximo de captura por armador" que estableció como medida de administración la distribución de la cuota anual de captura que corresponde al sector industrial entre los armadores que tuvieran a esa fecha autorizaciones de pesca vigentes, con una fórmula de cálculo que considera la historia de lo que había sido capturado por cada armador dentro de un período de tiempo determinado (derecho históricos) y, en algunos casos, a la capacidad de captura de las naves del armador que contara con naves con autorizaciones de pesca vigente. El "límite máximo de captura por armador" fue aplicado a diversas pesquerías nacionales y vence el 31 de diciembre de 2012.

El "límite máximo de captura por armador" no vino a alterar la naturaleza de las autorizaciones de pesca sino que se diseñó un sistema de cuotas sobre ellas, esto es, el acceso a la cuota del armador está determinado por la

\footnotetext{
${ }^{27}$ Es lo que se denomina el régimen de plena explotación.

${ }^{28} \mathrm{La}$ nave sustituta debe tener las mismas características de la nave sustituida, fundamentalmente en lo que se refiere a la capacidad de pesca porque el objetivo del cierre de acceso es no aumentar el esfuerzo que se realiza sobre la pesquería.

${ }^{29}$ Véase la nota 1.
} 
titularidad de una autorización de pesca, por el desempeño histórico y, en ciertos casos, por la capacidad instalada en las naves de sus titulares ${ }^{30}$.

\section{Naturaleza de las aUtorizaciones de PESCA}

\section{Naturaleza de las autorizaciones administrativas.}

La autorización de pesca es definida en la LGPA. como el acto administrativo mediante el cual la Subsecretaría faculta a una persona natural o jurídica, por tiempo indefinido, para realizar actividades pesqueras extractivas, con una determinada nave, condicionada al cumplimiento de las obligaciones que en la respectiva resolución se establezcan ${ }^{31}$.

En doctrina se diferencian los actos administrativos creadores de derechos y los que habilitan el ejercicio de derechos. En el primer caso se encuentran las concesiones que consisten principalmente en el otorgamiento del derecho exclusivo a un titular, por ejemplo, para usar o explotar un bien de dominio público o ejercer una actividad de servicio público. La concesión es título constitutivo y garantizador de un derecho a favor de un particular y, también, es el derecho que surge a partir de aquel título. En cambio, en el segundo caso se encontrarían las autorizaciones que se basan en el ejercicio de facultades de policía por parte de la Administración, de tranquilidad, seguridad y salubridad públicas y, que en definitiva, se orientan a levantar un obstáculo creado por dicha regulación de policía, para el ejercicio de un derecho preexistente, esto es, en virtud de la necesidad de ejercer un control previo de las condiciones de ejercicio de un derecho, se crea esta actuación estatal previa sin la cual el ejercicio del derecho, del cual ya se es titular, se vuelve ilegítimo.

Las autorizaciones se otorgan para realizar una acción material (por ejemplo, abrir farmacias) o para celebrar un acto jurídico (las que requieren los inferiores jerárquicos para efectuar ciertas adquisiciones). Frente a una determinada actuación, si el derecho para llevarla a cabo no existe procederá necesariamente la concesión, único instituto del derecho público necesario

${ }^{30}$ En virtud del artículo 9 de la Ley No 19.713 , por un acto voluntario del armador, puede cambiar una autorización de pesca por un certificado que da cuenta de los parámetros necesarios para fijar el LMC del armador respectivo, pero implica la necesaria salida de la nave de la actividad pesquera, esto es, el armador renuncia a la posibilidad que ejercer la actividad pesquera con esa nave y con cualquier otra porque da término a su autorización de pesca, conservando un instrumento que le permite seguir siendo titular de LMC con la cuota que le correspondía en virtud de la titularidad de la autorización y de la nave. La cuota obtenida con dicho certificado puede ser extraída por cualquier nave del armador que tenga autorización de pesca en la pesquería específica.

${ }^{31}$ Artículo $2 \mathrm{~N}^{\circ} 10$ LGPA. 
para obtener un derecho que jurídicamente no se tiene y que no se puede exigir ni reclamar. Si en cambio el derecho existe en el ordenamiento y la autoridad simplemente limita su ejercicio condicionándolo a determinadas circunstancias, procede la autorización. De este modo, la concesión es un acto creador de derechos inexistentes y la autorización un acto permisivo del ejercicio de un derecho preexistente. La primera es un acto constitutivo, la segunda un acto removedor de límites jurídicos ${ }^{32}$. "En efecto, si bien es cierto que la concesión y la autorización amplían la esfera jurídica de los administrados, la primera, no obstante, es un acto esencialmente creador de derechos, al paso que la segunda simplemente permite el ejercicio de un derecho ya existente, el que la autoridad, por razones de orden superior, generalmente de policía, se ve en la necesidad de restringir. Las autorizaciones no hacen otra cosa que remover el límite, la barrera u obstáculo jurídico que impedía el ejercicio de un derecho preexistente"33.

Según García de Enterría y Fernández Rodríguez ${ }^{34}$, los conceptos clásicos de autorización administrativa provendrían de Mayer (1895) y Raneletti (1893). Según el primero: "Acto administrativo que levanta la prohibición preventivamente establecida por la norma de policía, previa comprobación de que el ejercicio de la actividad inicialmente prohibida no ha de producir en el caso concreto considerado perturbación alguna para el buen orden de la cosa pública." Sería "prohibición bajo reserva de autorización, el juego de esta última se concreta en el restablecimiento de la libertad inicial del sujeto autorizado [...] que no recibe nada que no tuviera de antemano". Raneletti definió así: "La autorización [...] en la medida en que presupone la titularidad previa de un derecho, queda marcada por un neto carácter declarativo que la distingue con toda claridad de la concesión, acto por el que la Administración

\footnotetext{
${ }^{32}$ González Vergara, Ariel, La concesión, acto administrativo creador de derechos (Santiago, 1965), p. 35.

${ }^{33}$ Zanibini, Guidi, Curso de Derecho Administrativo, I, cit. por GonZález Vergara, Ariel, cit. (n. 32), p. 35; Silva Cimma, Enrique, Derecho administrativo chileno y comparado. Actos, contratos y bienes (Santiago, 1995, reimp. 2001), p. 83. Otro concepto de concesión es el que señala: "Aquella institución de derecho público administrativo que tiene la virtud esencial de ampliar la capacidad jurídica de un individuo determinado, esto es, dotarlo de un derecho que antes no tenía, ya sea producto de una traslación de derechos desde la Administración, ya por el nacimiento ex novo de derechos en el individuo por disposición del ordenamiento jurídico".

${ }^{34}$ García de EnTERría, Eduardo - Fernández, Tomás-Ramón, Curso de Derecho administrativo II (7a edición, Madrid, 2000, reimp. 2001), p. 135; GARCíA PÉREZ, Marta, La naturaleza jurídica de la autorización y la concesión, a propósito de la utilización del dominio público, en Anuario de la Facultad de Derecho de la Universidad de La Coruña, 1 (Galicia, 1997), p. 338.
} 
otorga derechos nuevos a un particular que, de este modo, ve enriquecido su patrimonio jurídico".

En consecuencia, la autorización administrativa, dentro de la cual podemos comprender la autorización de pesca, sería un acto administrativo que no crea un derecho o facultad para el individuo sino que actúa levantando un obstáculo que existía para el ejercicio de una libertad o derecho que ya es reconocido por el ordenamiento jurídico pero para el cual el propio ordenamiento ha previsto la necesidad de ejercer un control previo. Esto se funda en lo señalado en el capítulo III, en cuanto la autorización de pesca se basa en el establecimiento de un requisito necesario para el ejercicio de la libertad de adquirir el dominio de los recursos hidrobiológicos.

Cabe destacar lo afirmado por García de Enterría y Fernández Rodríguez $^{35}$ en cuanto el concepto de autorización antes planteado ha caído en crisis, debido a que se ha rebasado el ámbito del orden público que comprende la tranquilidad, seguridad y salubridad públicas, se ha trasplantado la autorización al complejo campo de las actividades económicas, donde su rol no se reduce el control negativo del ejercicio de los derechos, sino que se extiende a la regulación del mercado.

Reconociendo lo anterior, puede afirmarse que en el caso de la pesca, la autorización se basa, como se dijo previamente, en la necesidad de conservar los recursos hidrobiológicos, lo que indudablemente producirá un efecto en el mercado, de hecho toda regulación que de algún modo afecte una actividad económica, suele producir efectos en el mercado, pero las normas de la LGPA referidas a esta materia no tienen por objetivo ni están diseñadas en dicho sentido.

\section{Características que la LGPA le atribuye a las autorizaciones de pesca.}

La autorización de pesca habilita a la nave para realizar actividades pesqueras extractivas, sobre las especies y áreas que en ella se indiquen, está referida a una misma persona y no puede ser enajenada, arrendada ni puede constituirse a su respecto otros derechos en beneficio de terceros a ningún título, sin perjuicio de su transmisibilidad ${ }^{36}$.

La imposibilidad de enajenar la autorización y la relación entre la autorización y una nave específica se exceptúa cuando se declara el régimen de plena explotación y además se declara el cierre de acceso a una unidad de pesquería, puesto que el cierre de acceso no va aparejado necesariamente al régimen sino que debe declararse por acto separado ${ }^{37}$. En tal caso, la autorización de

\footnotetext{
${ }^{35}$ Ibíd., p. 136.

${ }^{36}$ Artículo 15 LGPA.

${ }^{37}$ Artículo 24 LGPA.
} 
pesca puede ser transferida en forma indivisible conjuntamente con la nave a la que se encuentra asociada ${ }^{38}$ y puede sustituirse la nave manteniendo la autorización de pesca, pero la nueva nave que reemplaza la anterior debe tener las mismas características que la nave original.

De este modo se asegura que la autorización de pesca siga validando una actividad que implique el mismo esfuerzo (impacto) para el que estaba autorizado el armador y, por ende, no se produzca a través de la sustitución un aumento del esfuerzo pesquero. Por último, en relación a las autorizaciones en régimen de plena explotación, tienen una duración indefinida m i e $\mathrm{n}$ t $\mathrm{ras}$ se mantenga la vigencia del régimen de plena explotación ${ }^{39}$ y siempre que no se constituyan causales de caducidad, esto es, la vigencia de la plena explotación está asociada a la vigencia del régimen respectivo, el que tiene un específico procedimiento de establecimiento y que puede ser sustituido por otros regímenes.

La autorización de pesca no garantiza a su titular la existencia de los recursos hidrobiológicos, sino que sólo le permiten, en la forma y con las limitaciones que establece la ley, realizar actividades pesqueras extractivas en una unidad de pesquería determinada ${ }^{40}$.

Como se dijo más arriba, la LGPA. contempla que las autorizaciones se otorgan por tiempo indefinido (con la salvedad descrita respecto del régimen de plena explotación) y se prevé como hipótesis de término tres situaciones: a) la configuración de una causal de caducidad; b) la declaración del régimen de recuperación; y, c) el término de vigencia del régimen de plena explotación. En el primer caso, el titular debe incurrir en una infracción a un deber del $\operatorname{armador}^{41}$; en el segundo caso, la sola declaración de un nuevo régimen de acceso denominado d e r e c u p e r a c i ó n tiene por efecto que expiren por el solo ministerio de la ley las autorizaciones de pesca otorgadas a esa fecha; en el tercer caso, es evidente que el cambio de régimen le pone término.

A modo de resumen se puede señalar: $i$ ) La autorización de pesca es un acto administrativo habilitante del ejercicio de la actividad pesquera, para un armador y nave determinados; $i$ ) No garantiza los resultados de la actividad pesquera ni una cuota determinada sobre los recursos hidrobiológicos; iii) La propiedad de los recursos hidrobiológicos surge por el ejercicio de la actividad pesquera, esto es, a través del modo de adquirir ocupación; iv) Es intransferible, a menos que la unidad de pesquería se declare en plena explotación, en cuyo caso la autorización puede transferirse en forma indivisible con la nave; $v$ ) Puede sustituirse la nave autorizada por otra de iguales característi-

\footnotetext{
${ }^{38}$ Artículo 23 LGPA.

${ }^{39}$ Artículo 23 LGPA.

${ }^{40}$ Artículo 31 LGPA.

${ }^{41}$ Artículo 143 LGPA.
} 
cas náuticas relevantes para efectos del esfuerzo pesquero, manteniendo la misma autorización; y vi) Es indefinida, sometida a causales de caducidad y de término por el solo ministerio de la ley en dos casos: al declararse el régimen de pesquería en recuperación o el reemplazo del régimen de plena explotación por el de general de acceso ${ }^{42}$.

\section{Otros actos administrativos generadores de situaciones juridicas favorables} a los particulares.

En el punto V.1 se hizo la distinción entre las concesiones y las autorizaciones como actos administrativos generadores de situaciones favorables a los particulares. A continuación se revisarán dos tipos de actuaciones administrativas específicas para analizar sus alcances: el permiso de edificación y la inscripción en el registro de transporte público remunerado de pasajeros.

a) Permiso de edificación. Los instrumentos de planificación urbana constituyen el estatuto de la propiedad inmueble urbana y rural, ya que definen las posibilidades de uso, destino, posibilidad de construcción y su extensión por parte de los particulares, en definitiva, el estatuto propietario inmueble se define (contenido y extensión de las facultades de uso, goce e incluso con incidencia en la disposición del bien) a través de la planificación. Sin embargo, estos instrumentos pueden cambiar en el tiempo planteándose diversas situaciones respecto de los particulares: estarán aquéllos que sometiéndose al instrumento de planificación habrán ejercido sus facultades y, por ejemplo, edificado más allá de lo que el actual instrumento permite como sí lo hacía el anterior, por lo que ante un cambio de estatuto que limite o prohíba la edificación, no se verán afectados. Simplemente no podrán volver a ejercer la facultad ahora prohibida. También estarán aquéllos que no habiendo ejercido la facultad de edificar que se otorgaba, con el cambio del instrumento de planificación habrán perdido esa expectativa por no haberla incorporado al patrimonio. Sin embargo, estarán también aquéllos que en el tiempo intermedio obtuvieron un permiso de edificación y no alcanzaron a concretarla.

En tales casos, corre a favor del particular el plazo de tres años de caducidad del permiso, sin que le sean aplicables las nuevas disposiciones que impiden el ejercicio de la obra proyectada. De este modo, se mantiene el derecho otorgado por el instrumento de planificación por un plazo determinado pero sólo respecto de quienes lo han ingresado en su patrimonio, mediante por ejemplo, la obtención del respectivo permiso. Según Rajevic "es indudable

${ }^{42}$ Independientemente de las dificultades fácticas que ello plantea, atendido que el procedimiento contempla intervención del Consejo Nacional de Pesca, donde se encuentran representados los propios actores de la actividad pesquera y, por ende, son titulares de un verdadero derecho de veto a una decisión de esta naturaleza. 
que una fuente cierta de derechos son los actos administrativos urbanísticos singulares.”³. En estos casos y por disposición expresa de la normativa, el permiso radica en el patrimonio del individuo las posibilidades que otorga el instrumento de planificación por un determinado período, las que de otra manera permanecen como meras expectativas para los particulares. En efecto, los permisos constituyen derechos ex novo para los particulares destinatarios de los mismos y, por ende, producen un efecto diverso respecto del patrimonio. De hecho, en la LGPA también se encuentran los permisos extraordinarios de pesca que otorgan un porcentaje de la cuota global de captura que se fije anualmente, lo que constituye obviamente un derecho que el particular no tendría sino en virtud de dicho acto administrativo.

b) Inscripción en el registro nacional de transporte público remunerado de pasajeros. En materia de la regulación del transporte público, por Ley No $18.696^{44}$ se creó un registro nacional de servicios de transporte de pasajeros como catastro global de todas las modalidades de servicios de transporte público de pasajeros en el que deben consignarse todos los antecedentes que el Ministerio de Transportes considere pertinentes para realizar fiscalizaciones y controles de los servicios de transporte de pasajeros. Sin embargo, en el caso del transporte público r e $\mathrm{m}$ u n e r a d o de pasajeros, la Ley No 19.940 estableció la obligación de inscribirse en dicho registro, otorgando al Ministerio la potestad de cobrar derechos por las actuaciones que en virtud de la administración de dicho registro deban realizarse ${ }^{45}$. En consecuencia, para el ejercicio de la actividad de transporte público remunerado de pasajeros se requiere como condición previa, la mencionada inscripción en el registro. Esto no difiere sustancialmente de una actividad estatal en ejercicio de potestades de policía en los términos descritos en el capítulo V, 1 .

Sin embargo, la inscripción en el mencionado registro de transporte de pasajeros ha sido sucesivamente suspendida desde el año $1998^{46}$ (tal como ha ocurrido con el registro pesquero artesanal en diversas pesquerías y con las autorizaciones de pesca en pesquerías en plena explotación). Atendida dicha situación, el reglamento del registro permite el reemplazo de los automóviles

${ }^{43}$ Rajevic Mosler, Enrique, La propiedad privada y de los derechos adquiridos ante la planificación urbana, en Revista Chilena de Derecho, 25 (Santiago, 1998) 1, p. 89. Cfr. El mismo, Derecho y legislación urbanistica en Chile, en Revista de Derecho Administrativo Económico, 2 (Santiago, julio-diciembre 2000).

${ }^{44}$ Artículo 3 inciso $7^{\circ}$.

${ }^{45}$ Artículo 10.

${ }^{46}$ Leyes números $19.593,19.700,20.076$ y 20.474. Esta última mantiene la medida hasta el 15 de noviembre de 2015, aunque incorpora algunas disposiciones que permiten en términos limitados y en casos calificados, autorizar nuevas inscripciones en el mencionado registro. 
inscritos ante el acaecimiento de determinados eventos, permitiendo a la vez el cambio de la inscripción, esto es, el propietario del vehículo que es reemplazado debe suscribir la solicitud de reemplazo conjuntamente con el propietario del vehículo reemplazante.

Obviamente desde el punto de vista patrimonial, la inscripción en el registro representa un valor para su titular desde el momento que el reemplazo en ella implicará, como es de suponer, la obtención de un precio por la transferencia. Sin embargo, dicha valoración económica no se desprende de la naturaleza misma de la inscripción sino del cierre de acceso previsto en este caso por ley y esto porque en el evento que no existiera el cierre de acceso, dicha inscripción no proporcionaría valor económico alguno a su titular. Por otra parte, para sostener la calidad de bien incorporal debe indicarse en qué consiste el poder que ella confiere. Podría señalarse que el contenido de la inscripción como bien incorporal es otorgar el derecho a ejercer la actividad económica de transporte de pasajeros, pero al sostener esto, se estaría planteando un derecho sobrepuesto a otro: la inscripción consistiría en el derecho a ejercer la actividad económica de transporte público de pasajeros. Podría señalarse por el contrario que lo que habilita la inscripción en el registro es el ejercicio de facultad de uso del vehículo motorizado, pero ello es inexacto porque la facultad de uso de un vehículo no es sólo el transporte público de pasajeros y para otros usos no se requiere una inscripción, por lo cual, lo que define el ámbito de utilidad o necesidad de la inscripción está dado por el ejercicio de dicha actividad económica, no otra. Si se sostuviera esta tesis, también tendría que afirmarse la calidad de bien incorporal del permiso de circulación sin el cual el vehículo simplemente no puede ser utilizado.

En consecuencia, en realidad el valor que se atribuye a la inscripción viene a estar dado por la exclusión de otros prestadores del servicio de transporte público remunerado de pasajeros, lo que implica que por la necesidad de racionalizar el transporte público lo que el Estado hace es trasladar la decisión de quien ingresa en este mercado cerrado a los particulares que circunstancialmente solicitaron la inscripción en el momento previo al cierre. En definitiva, la condición de cierre que tiene un fin público, proporciona un privilegio que se traduce en una ventaja económica para quien adquiere, en virtud del cierre, la decisión acerca de quién podrá ingresar o no a la actividad.

\section{LAS AUTORIZACIONES DE PESCA Y LA POSIBILIDAD DE SU} PROTECCIÓN POR EL DERECHO DE PROPIEDAD FRENTE AL LEGISLADOR

Conforme con lo dicho en el presente trabajo, corresponde analizar las consecuencias y la eventual protección que otorgaría a las autorizaciones 
de pesca el derecho de propiedad en el evento que el legislador decidiera ponerles término.

En primer lugar, el derecho de propiedad como tal derecho se configura por el legislador por lo cual no puede oponerse al ejercicio de la potestad legislativa los patrimonios de sujetos concretos. La distinción entre el plano objetivo y subjetivo de la propiedad lleva a señalar que respecto del primero, que es donde opera la regulación legislativa, sólo pueden verificarse las infracciones constitucionales que concreten la violación de la reserva legal (en este caso el potencial infractor no sería el legislador sino el poder ejecutivo) o del contenido esencial del dominio o si no se fundan en la función social las limitaciones y obligaciones impuestas a la propiedad o no se fundan sus restricciones en la protección del medio ambiente ${ }^{47-48}$. En consecuencia, no verificándose ese tipo de infracciones, es perfectamente constitucional la modificación legal del régimen de acceso a la pesca industrial.

Ahora bien, desde el punto de vista del derecho de propiedad en su aspecto subjetivo, cabe la pregunta acerca de un proyecto de ley que diera término a las autorizaciones de pesca vigentes, incurriría en una inconstitucionalidad. Acá debe considerarse si la autorización es o no un bien incorporal susceptible de propiedad. A tales efectos revisaremos los argumentos de Jorge Correa Sutil, Olga Feliú de Ortúzar y Santiago Montt Oyarzún, en los informes en derecho presentados al Tribunal de la Libre Comptencia.

\section{Posición planteada por Jorge Correa Sutil ${ }^{49}$.}

Correa parte de la idea que la pesca es una actividad prohibida y que, en consecuencia, mediante la autorización de pesca se otorga el d e r e cho a pe s c a r. Para justificar su afirmación considera que existe una infracción en la ley de pesca que consiste en ejercer la actividad pesquera sin contar con una autorización. Asimismo, adiciona como argumento las obligaciones que la Convención del Derecho del mar establece para el Estado ribereño de determinar la captura de recursos vivos permisible ${ }^{50}$. Entiende asimismo, que la autorización otorga derechos a su titular y, por ende, constituyen una propiedad para sus titulares.

También plantea que sería plausible que alguien sostuviera el carácter de

\footnotetext{
${ }^{47}$ Artículo $19 \mathrm{~N}^{\circ} 8$ inciso $2^{\circ}$ C.Pol.

${ }^{48}$ Aldunate Lizana, Eduardo, Limitación y expropiación, cit. (n. 2), pp. 285303.

${ }^{49}$ Correa Sutil, Jorge, Informe en Derecho (Santiago, 2010), presentado ante el Tribunal de la Libre Competencia por Asipes, Asociación de Industriales Pesqueros de la VIII región que representa al gremio que reúne a los principales titulares de los actuales LMC.

${ }^{50}$ Ibíd., p. 10.
} 
concesión de un bien nacional de uso público en cuanto la pesca se desarrolla en un espacio con dicha naturaleza: una suerte de concesión de derecho de uso del mar para pescar. Sin embargo, plantea que esta tesis no tendría mayor fundamento si se considera que el objeto de la pesca son los peces y no el uso del agua ${ }^{51}$.

Para Correa la esencia de la autorización de pesca no es la posibilidad de desarrollar actividades en el mar, sino es el de recho de a propiación de los peces ${ }^{52}$. Sin embargo, la LGPA. utiliza términos diversos para referirse a la pesca y a la acuicultura. En el primer caso, habla de autorización (artículo $2 \mathrm{~N}^{\circ} 10$ ) y consiste en el acto administrativo que faculta a una persona para ejercer la actividad pesquera extractiva, en cambio, en materia de acuicultura la LGPA. habla de concesión (artículo $2 \mathrm{~N}^{\circ} 12$ ), la que consiste en un acto administrativo que otorga los derechos de uso y goce sobre determinados bienes nacionales. Si se sigue la tesis de Correa, no se explica entonces que el mismo legislador utilizara términos diversos para referirse a una misma situación jurídica: otorgamiento de un derecho que no se tiene en forma preexistente.

Por otra parte, Correa sostiene que la ley de pesca es una de aquéllas que exige el artículo $19 \mathrm{~N}^{\circ} 24 \mathrm{C}$.Pol. en cuanto por ley se regula los modos de adquirir y de hecho la pesca es un modo de adquirir los peces. Asimismo, asigna la calidad de bien incorporal a la autorización de pesca en cuanto es adquirida por un titular, ingresa a su patrimonio, tiene una utilidad patrimonial y es evaluable en dinero, lo que se expresa en el mercado cuando la nave es transferida ${ }^{53}$.

Concluye, señalando que lo consustancial de la autorización de pesca es conceder el derecho a realizar actividades pesqueras en conformidad a la ley y que el derecho de propiedad se vería afectado si una eventual nueva regulación legal desconoce estas autorizaciones.

Contrariamente al planteamiento de Correa, la prohibición general del ejercicio de la actividad pesquera de la que parte su análisis, se opone al artículo $19 \mathrm{~N}^{\circ} 23$ C.Pol. que reconoce a todos los individuos la libertad para adquirir el dominio toda clase de bienes, por lo cual no puede sostenerse que los recursos hidrobiológicos constituyan una categoría de bienes excluidos de la libre apropiación privada. La técnica constitucional es establecer requisitos o limitaciones, no prohibiciones, salvo respecto de los bienes que la naturaleza ha hecho comunes a todos los hombres y los que deban pertenecer a la Nación toda y la ley lo declare así. Al señalar que lo esencial de la autorización de

\footnotetext{
${ }^{51}$ Ibíd., p. 23.

${ }^{52}$ Ibíd., p. 31.

${ }^{53}$ Ibíd., p. 50-51.
} 
pesca no es desarrollar actividades en el mar sino el derecho a la apropiación de los peces, confunde el requisito constitucional necesario (autorización) para el ejercicio de la libre apropiación de esta clase de bienes. Finalmente, en cuanto la autorización de pesca sería un modo de adquirir los peces, confunde la autorización con la ocupación, esto es, la actividad material que se concreta en la captura puesto que la autorización de pesca, como se dijo en el capítulo $V$, no garantiza el resultado de la actividad ni la captura, solo habilita el ejercicio de la libre adquisición. Dejaremos para el final de este apartado el análisis de la autorización como bien incorporal.

Por su parte, la Convención del Mar no establece una prohibición de captura de los recursos en la zona económica exclusiva de los particulares, sino que delimita el ámbito de potestades que se reconoce al Estado ribereño que declara, conforme al derecho internacional, su zona económica exclusiva. En efecto, la disposición sobre zona económica exclusiva se refiere a derechos de soberanía, jurisdicción y otros derechos y deberes del Estado ribereño. El hecho que se establezca que el Estado fijará cuotas permisibles de captura implica un deber, en el marco de la conservación de los recursos y bajo ningún punto de vista contiene ni requiere tener implícita una prohibición para el ejercicio de la pesca. Además sería un contrasentido porque lo que hace la Convención del Mar en el artículo 56 es reconocer al Estado ribereño la facultad, entre otras, de conservación, por lo cual mal podría la Convención desconocer dicha facultad imponiendo una prohibición de captura ajena a la voluntad del Estado ribereño.

\section{Posición planteada por Olga Feliú de Ortúzar ${ }^{54}$.}

Feliú sitúa las autorizaciones dentro de lo que se denominan los actos favorables ${ }^{55}$ que puede dictar la Administración, cuya revocación está condicionada por la ley, por reconocer o declarar derechos o facultades a los destinatarios. A diferencia de la concesión, "el derecho o facultad no lo crea, constituye o traslada la autorización, sino que está previamente en el patrimonio o en el ámbito de la libertad particular pero cuyo ejercicio sólo es lícito después que la Administración constata la existencia y límites del derecho o de la libertad, o que no existen motivos contrarios a su plena efectividad." ${ }^{56}$.

Pese a que Feliú afirma -apoyada en la cita de otros autores- la posición

${ }^{54}$ Feliú De ORTúzar, Olga, Informe en derecho (Santiago, 2010), presentado ante el Tribunal de la Libre Competencia por Asipes, Asociación de Industriales Pesqueros de la VIII región que representa al gremio que reúne a los principales titulares de los actuales LMC.

${ }^{55}$ En contraposición a lo que son los actos de gravamen.

${ }^{56}$ Carmona Santander, Carlos, Apuntes de Derecho Administrativo (Univer- 
en torno a que la autorización de pesca es un acto favorable que no crea derechos sino que elimina una cortapisa para el ejercicio de un derecho pre existente, concluye sin mayor explicación que el titular de la autorización de pesca es dueño de un bien incorporal sobre el que conforme al artículo 583 del Código Civil recae una especie de propiedad. A esto agrega que el hecho de tener la autorización duración indefinida y ser transferible con la nave (en el caso de las autorizaciones en régimen de plena explotación) son elementos de juicios que permiten sostener que sus titulares tienen un derecho de propiedad sobre una cosa (sic) incorporal. Concluye señalando que las autorizaciones sólo pueden ser expropiadas mediante una ley que cumpla los resguardos constitucionales.

En cuanto a la duración indefinida de la autorización resulta discutible que ello implicara el congelamiento de la situación de hecho en que ella consiste, porque precisamente la propia ley contempla su término ante la eventualidad del establecimiento de un régimen de pesquerías en recuperación. En consecuencia, el carácter de indefinido debe ser interpretado en su sentido natural y obvio: no tiene fecha d e fin id a de término, lo que no significa que sea perpetua como parece ser la interpretación que se le da. Por lo demás, no puede sostenerse que el legislador incurre en una supuesta afectación del derecho de propiedad por dejar sin efecto las autorizaciones de pesca vigentes cuando ya la LGPA. contempla la posibilidad de término de las mismas por vía administrativa cuando se cambia el régimen de plena explotación por el de recuperación o general de acceso. En cuanto a la calidad de transferible de la autorización de pesca, ella está condicionada a la mantención de la situación de hecho que llevó al cierre de acceso, esto es, si en la pesquería respectiva se constatara una recuperación que justificara el levantamiento del régimen de plena explotación ¿podría invocarse la mantención del mismo porque se afecta el contenido patrimonial de la autorización ya que pierde dicho carácter transferible y, seguramente, también el valor de mercado que mantiene con el cierre de acceso?

\section{Posición planteada por Santiago Montt Oyarzún ${ }^{57}$.}

Montt plantea que si bien el derecho de propiedad ampara toda clase de titularidades de contenido patrimonial, las autorizaciones de pesca no revisten ese carácter por lo cual no existe propiedad susceptible de ser expro-

sidad de Chile, 2003), p. 33. cit. por Feliú, Olga, en Informe en Derecho (Santiago, 2010), p. 16.

${ }^{57}$ Montt Oyarzún, Santiago, Informe en Derecho (Santiago, 2010), presentado por la empresa pesquera que solicitó la intervención del Tribunal de la Libre Competencia y, por ende, plantea la no existencia de un derecho de propiedad posible de ser afectado por un cambio de régimen. 
piada frente a un cambio regulatorio. En efecto, y citando a Sayagués Lazo y Carmona Santander, afirma que la autorización no crea derechos, sino que simplemente remueve los límites a una actividad en principio libre ${ }^{58}$. Asimismo, las autorizaciones en régimen general de acceso no tendrían valor económico alguno por permitir el acceso a cualquier interesado y ser personalísimas, no pudiendo ser transferidas ni constituir sobre ellas derechos a favor de terceros ${ }^{59}$.

Las autorizaciones de pesca en régimen de plena explotación no escapan al mismo carácter de actos favorables que no crean derechos y los intereses económicos que se generan para sus titulares son meros reflejos de las prohibiciones a que quedan sujetos los terceros, esto es, se trataría de un privilegio fáctico no constitutivo de derechos ${ }^{60}$. La autorización de pesca en régimen de plena explotación no muta "en propiedad susceptible de ser expropiada. El valor económico de la autorización de pesca [...] no está respaldado jurídicamente por la creación de titularidades o derechos subjetivos. La acumulación legal-administrativa de restricciones, limitaciones y prohibiciones que impide a nuevas firmas a entrar en la industria pesquera extractiva [...] no crea derechos a favor de los titulares de las autorizaciones." ${ }^{61}$

En definitiva para Montt la autorización de pesca en régimen de plena explotación debe ser calificada de privilegio fáctico, un mero espejismo de una prohibición correlativa que inhibe a los competidores pero no una propiedad susceptible de ser expropiada ${ }^{62}$.

Efectivamente, la autorización de pesca es transferible en la medida en que se mantiene el régimen de plena explotación el que podría señalarse, no dice relación con la naturaleza misma de la autorización sino como un efecto legal aparejado al cierre de acceso. Tanto es así que reemplazado el régimen de acceso, por el general o el de pesquería en recuperación, pierde el carácter transferible o simplemente se extingue. Esto se ve confirmado por el hecho que en el caso de las concesiones, donde efectivamente el acto administrativo es constitutivo de derechos y, por ende, lo otorga, también puede ser sometido a cierre de acceso ${ }^{63}$ sin que dicho cierre altere la naturaleza del acto concesional, sino simplemente traslada al particular titular

${ }^{58}$ Ibíd., p. 21.

${ }^{59}$ Ibíd., p. 22.

${ }^{60}$ Ibíd., p. 24.

${ }^{61}$ IBÍD., p. 26.

${ }^{62}$ Ibíd., p. 26.

${ }^{63}$ Recientemente las Leyes № 20.434 (DO. de 8 de abril de 2010) y № 20.583 (DO. 2 de abril de 2012) han cerrado el acceso a las concesiones de acuicultura de salmones en la región de Los Lagos y a todo tipo de concesión de acuicultura en la región de Aysén. 
de la concesión, la potestad estatal de decidir el ingreso de nuevos actores mediante la transferencia. Asimismo, la autorización no constituye un bien independiente de la nave porque aún en el evento de poder ser transferida solo puede serlo junto con la nave y además no puede ser dividida. En último término lo que podría decirse que lo que se podría perder, es que terminado el cierre se pierde este privilegio otorgado mediante la transferibilidad de la autorización.

Podría decirse que dicho privilegio es equivalente a cualquier norma transitoria que salva los derechos adquiridos en virtud de una nueva legislación puesto que se generan igualmente diversos estatutos: uno para quienes mantienen el derecho adquirido al amparo de la anterior legislación y quienes deben someterse al nuevo estatuto. Sin embargo, ya se ha señalado que la autorización de pesca no constituye derecho adquirido y además el privilegio en este caso se constata por la e x cl u s i ó n de otros actores. En efecto, en la medida que se ha mantenido el cierre de acceso que excluye a otros actores de la actividad pesquera se ha mantenido una situación que constituye un verdadero privilegio fáctico que no ha sido otorgado con ese contenido por parte del Estado, por lo que mal puede atribuirse a este último una voluntad en el sentido de la mantención en el tiempo de una autorización que adquirió el carácter de un verdadero privilegio fáctico, no jurídico. En consecuencia, si el legislador decide modificar la forma de otorgar el acceso a la actividad pesquera, manteniendo el objetivo de conservación de los recursos, nada obsta su potestad de administración de los recursos hidrobiológicos puesto que no le son oponibles los privilegios fácticos que han surgido del cierre de acceso.

Montt también rechaza la eventual posición acerca de una posible expropiación derregulatoria, esto es, una nueva regulación que al desconocer las autorizaciones de los armadores actualmente autorizados causara una afectación del derecho de propiedad por la pérdida de valor económico en los activos invertidos para el ejercicio de la actividad pesquera, los que pueden empezar a ser subutilizados o volverse inútiles ante el cambio de regulación.

Este último aspecto no se vincula directamente con la naturaleza de la autorización de pesca sino que enfoca la discusión en la afectación patrimonial que sufren los armadores pesqueros actualmente autorizados al verse expuestos a que se alteren los supuestos sobre los cuales ejercen su actividad $y$, en definitiva, aquéllos en los que se fundaron sus inversiones. Se puede afirmar que es un costo de la legislación que debe soportar todo ciudadano puesto que en este ámbito la vigencia de la ley de "límite máximo de captura por armador" otorgó un beneficio restringido a estos armadores y dicho beneficio tenía fecha de término. 
3. Las autorizaciones de pesca no son bienes incorporales susceptibles de propiedad.

Como se dijo en el capítulo II supra los bienes incorporales consisten en derechos (poderes o facultades) otorgados o reconocidos en último término por el ordenamiento jurídico, de carácter patrimonial, cuya titularidad exclusiva es reconocida a un sujeto quien puede disponer de ellos. De lo señalado previamente, la autorización de pesca reviste algunos de estos caracteres pero otros solo aparenta revestirlos.

En efecto la autorización de pesca está otorgada a un titular exclusivo, quien puede disponer de ella solo ante la declaración del estado de plena explotación de la pesquería, la que puede terminar dependiendo de la concurrencia de hechos que dependen de una decisión de la Autoridad en conjunto con el Consejo Nacional de Pesca y de los Consejos Zonales de Pesca. Esto es, la facultad de disposición sobre la autorización y la mantención de ella, no están entregadas como potestad propia del titular de la autorización sino a eventos externos a su voluntad.

Por su parte, la autorización no otorga nuevos derechos sino que permite el ejercicio de una libertad constitucional: la libre apropiación de los recursos hidrobiológicos, por lo cual el carácter patrimonial no se encuentra en la autorización de pesca sino en el resultado de la actividad de pesca que se concreta en la ocupación de los recursos hidrobiológicos. En otras palabras, de la libre apropiación de los recursos hidrobiológicos todos somos titulares por mandato constitucional (artículo $19 \mathrm{~N}^{\circ} 23 \mathrm{C}$.Pol.) y el hecho que hoy algunos tengan autorización y que no cualquiera pueda hacer ejercicio de esta libertad constitucional viene dada por un cierre de acceso declarado en forma separada al régimen de plena explotación, lo que se ha traducido en el traslado, desde el Estado al particular, de la decisión de quien puede ingresar a la actividad pesquera, lo que se constituye no como un derecho otorgado por el ordenamiento jurídico sino como un privilegio que surge como efecto colateral al cierre de acceso necesario para la conservación de los recursos. Esto excluye un posible atentado a la igualdad ante las cargas públicas porque por el contrario, quienes detentan las autorizaciones de pesca en la actualidad son los únicos que pueden ejercer esta libre apropiabilidad de los recursos hidrobiológicos reconocida constitucionalmente a todos. Solo haciendo un gran esfuerzo sería posible describir el término de las autorizaciones de pesca como un sacrificio especial que no es tolerable ni aceptado por la Constitución.

Y esto puede afirmarse por un ejercicio sencillo: ¿tendrían valor patrimonial las autorizaciones de pesca en régimen de plena explotación, que como se sabe, en este régimen son transferibles, si conjuntamente con dicho régimen no se declarara el cierre de acceso a la pesquería? En efecto, conforme al 
artículo 24 LGPA. vigente el régimen de plena explotación la Subsecretaría continuará otorgando autorizaciones de pesca a quienes las soliciten y, sólo por una decisión a la que concurren la Subsecretaría de Pesca, y los Consejos Nacional y Zonales de Pesca se puede establecer el cierre de acceso. En esta hipótesis cabe pensar que en realidad el valor patrimonial no vendrá dado por la autorización sino por la actividad que ejerza el armador. Sin cierre de acceso ¿qué diferencia tiene la autorización de pesca con el permiso de circulación de los vehículos motorizados?

En consecuencia, el Estado, en ejercicio de su facultad de administración de los recursos hidrobiológicos, podría decidir recuperar la potestad de decidir la forma en que los particulares acceden al ejercicio de una libertad constitucionalmente reconocida, por lo cual nada impediría que el legislador así lo determinara dando término a las autorizaciones de pesca.

\section{ConClusión}

Conforme se ha señalado en el presente trabajo, ante una nueva regulación que el legislador hiciera del acceso a la actividad pesquera industrial dando término a las autorizaciones de pesca no se derivarían consecuencias desde el punto de vista del derecho de propiedad:

a) Al ubicarse la discusión sobre las autorizaciones de pesca en el ámbito de los bienes incorporales no lo alcanza la protección del contenido esencial del dominio que dice relación con los bienes corporales.

b) Al distinguir ambos planos del derecho de propiedad y ubicarse la situación de los actuales armadores industriales en el plano subjetivo, se puede concluir que el legislador no está privado de generar una nueva regulación, trasladando una eventual discusión al ámbito de la responsabilidad del Estado y el posible atentado a la igualdad ante las cargas públicas.

c) La autorización de pesca no es un bien incorporal por cuanto no otorga un derecho independiente o autónomo sino que habilita el ejercicio de un derecho preexistente: el derecho a ejercer la libertad de apropiación de los recursos hidrobiológicos. Siendo esta última reconocida constitucionalmente, si se considera la autorización de pesca como un bien incorporal se afirmaría un derecho de propiedad sobre un acto intermedio para ejercer una libertad reconocida constitucionalmente. La autorización de pesca tampoco implica un valor patrimonial por sí misma, porque aún siendo transferible, no tendría valor alguno si no existiera el cierre de acceso a la pesquería.

d) No resulta plausible sostener que el término de las autorizaciones de pesca conlleve un atentado a la igualdad ante las cargas públicas porque quienes pueden ejercer la libertad de apropiación de los peces lo hacen como un privilegio frente a todos los demás individuos titulares de la libre apropiación 
de los bienes. Dicho privilegio se genera por el cierre de acceso que no es un paso necesario al régimen de plena explotación.

\section{BIBLIOGRAFÍA}

Aldunate Lizana, Eduardo - Fuentes Olmos, Jessica, El concepto del derecho de propiedad en la jurisprudencia constitucional chilena y la teoria de las garantias de instituto, en Revista de Derecho de la Universidad Católica de Valparaíso, 18 (Valparaíso, 1997).

Aldunate Lizana, Eduardo, Jurisprudencia constitucional 2006-2008. Estudio selectivo (Santiago, 2009).

Aldunate Lizana, Eduardo, Deficiencias en la argumentación jurídica. Comentario crítico al fallo del Tribunal Constitucional librado en la causa rol $N^{\circ} 207$, en Revista de Derecho de la Universidad Católica de Valparaíso XVI (Valparaíso, 1995).

Aldunate Lizana, Eduardo, Limitación y expropiación. Scilla y Caribdis de la dogmática constitucional de propiedad, en Revista Chilena de Derecho 33 (Santiago, 2006), 2.

Cordero Quinzacara, Eduardo, Las garantias institucionales en el Derecho alemán y su proyección en el derecho de propiedad, en Revista de Derecho de la Universidad Católica del Norte, 14 (Coquimbo, 2007) 2.

Cordero Quinzacara, Eduardo, La dogmática constitucional de la propiedad en el derecho chileno, en Revista de Derecho de la Universidad Austral de Chile, 19 (Santiago, 2006) 1.

Correa SutiL, Jorge, Informe en Derecho (Santiago, 2010), presentado ante el Tribunal de la Libre Competencia en www.tdlc.cl, última visita 08/12/2010.

Feliú de OrTúzar, Olga, Informe en Derecho (Santiago, 2010), presentado ante el Tribunal de la Libre Competencia, en www.tdlc.cl, última visita el 8 de diciembre de 2010.

García de Enterría, Eduardo - Fernández Rodríguez, Tomás-Ramón, Curso de Derecho administrativo (7ª edición, Madrid, 2000, reimp. 2001).

García Pérez, Marta, La naturaleza jurídica de la autorización y la concesión, a propósito de la utilización del dominio público, en Anuario de la Facultad de Derecho de la Universidad de La Coruña, 1 (Galicia, 1997).

González Vergara, Ariel, La concesión, acto administrativo creador de derechos, (Santiago, 1965)

GUZMÁN BRITO, Alejandro, Las cosas incorporales en la doctrina y en el derecho positivo ( $2^{a}$ edición, Santiago, 2006).

Montt Oyarzún, Santiago, Aplicación de los tratados bilaterales de protección de inversiones por tribunales chilenos. Responsabilidad del Estado y expropiaciones regulatorias en un mundo crecientemente globalizado, en Revista Chilena de Derecho, 32 (Santiago, 2005) 1.

Montt Oyarzún, Santiago, Informe en Derecho (Santiago, 2010), presentado ante el Tribunal de la Libre Competencia, en www.tdlc.cl, última visita 8 de diciembre de 2010.

Rajevic Mosler, Enrique, Derecho y legislación urbanistica en Chile, en Revista de Derecho Administrativo Económico, 2 (Santiago, julio-diciembre 2000). 
Rajevic Mosler, Enrique, La propiedad privada y de los derechos adquiridos ante la planificación urbana, en Revista Chilena de Derecho, 25 (Santiago, 1998) 1.

Silva Cimma, Enrique, Derecho administrativo chileno y comparado. Actos, contratos y bienes (Santiago, 1995, reimp. 2001) 
